\title{
Developing Strategies to Cope with Academic Disparities
}

\author{
Anand Mahanand \\ EFL University, Hyderabad-500605, India \\ Email: amahanand991@gmail.com
}

\begin{abstract}
The aim of the paper is to study the academic conditions of students who come from deprived background and from the rural areas to join universities at the M.A. level and suggest strategies to cope with academic challenges faced by them. The paper assumes that there exists a large gap between students who come from rural areas and from the deprived sections and academic expectations demanded by educational institutions. It studies the nature of their problems and suggests measures to deal with such difference. It also reports an experiment done to improve academic skills of such students.
\end{abstract}

Index Terms—strategies, disparities, academic skills, regional medium, cognitive ability, performance

\section{INTRODUCTION}

The composition of university classroom today is different from what it used to be about sixty years back. About sixty years back, the classroom was predominately occupied by students from the feudal/upper class. The classroom was of homogenous nature. The methodology used was common and the problems faced by the students were also common. After Independence, with the democratization of education, the composition of students in the universities has changed. There has been an inflow of students from rural areas and from the underprivileged sections recognized by the constitution as scheduled castes and scheduled tribes. Some of them are first generation learners. They went through disadvantaged schools and through regional medium education. They have little exposure to English language. Their surroundings are far away from contact of English. They lack literature in English to read. They hardly have any audiovisuals at home to provide them exposure to the language. They hardly have relatives on whose visits they can converse in English. The world outside home also does not give them adequate exposure to the use of English. At the school and in some cases, at the college level also the medium of instruction is not English. They learn English just as a subject. But at the university there is a sudden shift to English. At the M.A. level, the medium of instruction is English. Even though they have cognitive ability, they find it difficult to cope with the academic demands made by the universities. As a result they develop some kind of inferiority complex. They are also looked down upon by many teachers as incompetent and inefficient and not so hard working. Needless to say, their performance is low. As a result, they feel frustrated and discriminated. Some give up their courses. Some register protests. The managers of higher education feel that they are not fit to come to the university. Instead, they should be working in the fields or doing some other job but not at the temples of learning. There are hardly any efforts to address this problem. Some universities have Centres for English Language Teaching (CELTs). They ought to address problems of this kind. But a very few have courses meant for this kind of learners. The UGC has been funding to conduct remedial classes for such students in universities. Some are conducting such classes sincerely. Even here there are some problems. Students have to attend classes in addition to their regular classes. So they become overburdened with work. As an alternative they tend to neglect their remedial classes and give more importance to their core courses. Some students do not show interest as they don't want to be categorized as a group for such a course because some kind of stigma is attached to it.

It is the need of the hour to find out ways and means to tackle this problem. The CELTs should be activated and assigned this task to do in an effective manner. Where there are no CELTs, effort should be made to open new ones and the UGC should urge them to study this problem in a systematic manner and design courses and materials to cater to the needs of the students.

\section{THE RESEARCH PROBLEM}

Keeping these problems in mind, the author under took up a small research project to study the academic problems faced by M.A. students from the deprived communities and students with a regional medium background enrolled in University departments where the instruction is primarily in English.

Through initial personal interviews through questionnaires (appended) and discussions with such students at his University (EFL-U), Hyderabad he found that these students lacked academic skills. In other words they were unable to do the following:

- read and comprehend their texts and make notes from them,

- listen to lectures and take down notes with discrimination, 
- write well-prepared and well-organized essays, papers and reports

- produce well presented answers in exam in various subjects

- express/explain ideas and arguments

- use the dictionary in an efficient way

- organize their study in an effective manner.

Their syllabus did not equip them to handle all these skills in English. All these skills were necessary to cope with the academic demands made by an M.A. programme. The ability to succeed and do well in the MA examinations largely depended on the above mentioned skills.

A possible way of overcoming the situation was to help them organize their academic skills which included academic reading and academic writing, speaking and reference skills. This was done through a Course in Academic Skills which helped them with reading, writing, speaking, and reference skills in academic contexts and there was a significant difference in their performance. Since then a course in English for Academic Purposes is on offer as an optional course as part of M.A. programme.

\section{RESEARCH METHOD}

A micro level analysis of students needs was carried out to study the areas in which students needed real attention. Taking those problems into account detailed lessons were written based on the framework of the outline. A diagnostic test was conducted among the target group of students to know their entry level in the beginning of the semester. Then these materials were trialled with them through the monsoon semester August-November 2008.The class duration was two hour and mostly task based. Students were engaged in doing different tasks on academic skills. These were moderated by the tutor.

\section{RESULTS AND FINDINGS}

Again an exit level test was conducted and it was found that these materials were quite effective. There was a significant improvement in the target areas. A table showing their improvement (difference) has been appended. Feedback received from students on the course has been very encouraging. Two samples appended. The target group of students (twenty in number) were not segregated from other students but were taught along with other classmates (as the researcher felt that segregation gives rise to stigma). The course has been introduced for the students of M.A. programme at the EFL University, Hyderabad. And it has been made an optional course and being taught regularly. The course out- line and samples of materials have been given below.

\section{Course Outline}

(Components)

Unit I: Academic Reading (of different kinds of texts)

a. What is Skimming?

b. How to Skim?

c Scanning

d. What is Scanning?

e. How to Scan?

f. Comprehension Practice (Literary appreciation, information transfer)

g. guessing meaning from contexts, predicting,

$\mathrm{h}$. Understanding main ideas, understanding text organization

Suggested Reading:

Greenall, S. (1986). Effective Reading Skills for Advanced Learners. Cambridge: CUP.

Swan, M.(1978). Understanding Idea: Advanced Reading Skills . Cambridge: CUP.

Richards, J.C.(2003). Strategic Reading: Building Effective Reading Skills. Cambridge: CUP.

\section{Unit II: Academic Writing}

a. Note-making from texts

b. Note-taking from Lectures

c. Summarizing

d. Writing an Essay/Paper/Review

\section{Suggested Reading:}

Leki, I.(1989). Academic Writing. New York: St. Martin Press.

Grellet, F.(2008). Writing for Advanced Learners. Cambridge: CUP.

Cholij, M. (2007). Towards Academic English: Developing Effective Writing Skills. Delhi: Foundation Books.

\section{Unit III: Reference Skills (Dictionary skills)}

a. Using the dictionary 
b. How the entries work (Finding headwords)

c. Finding guide words

d. Abbreviations

e. Pronunciation and Spelling

f. Usage

\section{Suggested Reading:}

Leancy, Cindy. (2007). Dictionary Activities. Cambridge: CUP.

Smith, Mike and Glenda Smith. (1990). A Study Skills Handbook. Oxford: OUP.

Tickoo, M.L.(2007). Teaching and Learning English: A Source Book for Teachers and Learners. Delhi: Orient Blackswan.

\section{Unit IV: Academic Listening}

a. Listening to lectures

b. Comprehending (understanding the main and the subsidiary points

c. Taking notes

\section{Suggested Reading:}

Lynch, T.(1983). Study Listening.Cambridge:CUP.

Sanabira, K. (2004). Academic Listening Encounters. Cambridge: CUP.

\section{Unit V: Speaking for Academic Purposes}

a. asking questions in lectures

b. participation in seminar/discussions

c. making oral presentations, answering ensuing questions/points

d. verbalizing data, and giving oral instructions, in seminars/workshop

Suggested Reading:

Bradbury, A. (2006).Successful Presentation Skills. Delhi: Kogan Page. Emden, Joan and Lucinda Bechen. (2004). Presentation Skills for Students. New York: Palgrave.

Rogerson, Pamela and Judi B. Gilbert.(2004). Speaking Clearly. Cambridge: CUP.

Lynch, Tony and K. Anderson.(1992). Study Speaking. Cambridge: CUP.

\section{General Reading:}

Jordan, R.R.(2004). English for Academic Purposes. Cambridge: CUP.

Flowerdew and Peacock.(1994). Research Perspectives on English for Academic Purposes. Cambridge: CUP.

Wallace, M.J.(1980). Study Skills in English. Cambridge: CUP.

In addition to all these, there are other ways to deal with this problem. Where there is the system of internal assessment through assignments and projects, teachers need to guide these students with a lot of patience and understanding. They need to look at the their assignments with care and appreciate the good points present in the write up and also give feed back at different stages, instead of just awarding a final judgment on it. Their writing process should also be guided properly. Some universities abroad have support centers where students and teachers come forward to help the needy students writing their assignments, proofreading and so on. This task also can be taken up the CELTs. This could be done without making the student conscious of their disability. It is also important to recognize that these students have cognitive ability and skills in their L1. That should be capitalized. And their linguistic ability could be built up.

Efforts should also made to observe learning strategies of high achievers from this section. There are many students who come from this background but do successfully well in their studies. It is worthwhile studying their strategies of study and this may help other students.

\section{CONCLUSION}

Students need academic skills to cope with their academic programmes. If they are initiated in these skills they will find it easy to organize their studies in an independent manner. They will not only fair well in the courses they are enrolled in but also these skills will help them in their studies they will take up later. A vast amount of human resource will be empowered. Their future will be safer and brighter.

Notes: $\mathrm{SC}=$ Scheduled Castes, $\mathrm{ST}=$ Scheduled Tribes, UGC $=$ University Grants Commission, EFL-U=English and Foreign Languages University

\section{APPENDIX A: SURVEY}

1.Total no. of respondents

2. Scheduled Castes/Tribes $\quad 30$

3. Backward Castes 10

4. From rural areas 22 
5. From urban areas 18

6. From regional medium 30

7. From English medium 10

8. No of students who take active part in discussions:(often) 10

(rarely) 25

(never) 05

9. Reasons for not taking part: (feel shy) 08

(unable to express in English) 18

(Does not required ) 14

10. No. of students who can read and understand prescribed texts

$\begin{array}{ll}\text { Yes } & 13 \\ \text { No } & 07 \\ \text { To some extent } & 20\end{array}$

11. No. of students who have problems in Writing assignments

$\begin{array}{cr}\text { Yes } & 26 \\ \text { No } & 14\end{array}$

12. No of students who can understand lectures

$\begin{array}{ll}\text { Yes } & 11 \\ \text { No } & 08 \\ \text { To some extent } & 21\end{array}$

13. No. of students who want to improve their academic English

$\begin{array}{lr}\text { Yes } & 27 \\ \text { No } & 13\end{array}$

\section{APPENDIX B A SAMPLE OF THE QUESTIONNAIRE}

This survey is meant for a research paper. Please don't hesitate to supply information. Your identity will be kept confidential. Thank you.

1. Name:

2. Social Status: OC/SC/ST/OBC

3. You are from (a) rural area (b) urban area

4. Your subject:

5. You studied in English medium/ Regional medium before joining the university.

6. What is your average Grade/Marks in your M.A. so far?

7. How often do you take part in classroom discussion?
a. Often
b. Rarely
c. Never

8. Do you find it difficult to participate in class discussion/speak in the class?

a. Yes__ b. No

9. What are the reasons?

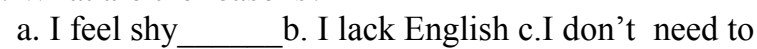

10. Can you read and understand the books and materials prescribed for you?
a. Yes
b. No. c. to some extent

11.Do you find it difficult to write an assignment?

a. Yes b. No

12.If you find it difficult, what are the reasons?

a. I can't express in writing even though I have ideas__. a. I make mistakes

13. Can you understand the lectures delivered by your professors?
a. Yes
b.No
c. To some extent

14. Do you want to improve your English to use academic contexts?
a. Yes b. No

APPENDIX C RESUlT OF TESTS AND THE DIFFERENCE 


\begin{tabular}{|l|l|l|l|}
\hline Student & Pre-test (100 Marks) & Post-test (100Marks) & Difference \\
\hline 1 & 45 & 90 & 45 \\
\hline 2 & 45 & 95 & 50 \\
\hline 3 & 40 & 90 & 50 \\
\hline 4 & 45 & 85 & 40 \\
\hline 5 & 45 & 90 & 45 \\
\hline 6 & 40 & 90 & 50 \\
\hline 7 & 45 & 90 & 45 \\
\hline 8 & 40 & 55 & 55 \\
\hline 9 & 40 & 90 & 50 \\
\hline 10 & 45 & 90 & 45 \\
\hline 11 & 40 & 90 & 50 \\
\hline 12 & 35 & 85 & 50 \\
\hline 13 & 35 & 85 & 50 \\
\hline 14 & 45 & 90 & 45 \\
\hline 15 & 40 & 85 & 45 \\
\hline 16 & 35 & 85 & 50 \\
\hline 17 & 50 & 95 & 45 \\
\hline 18 & 40 & 90 & 50 \\
\hline 19 & 40 & 90 & 50 \\
\hline 20 & 45 & 95 & 50 \\
\hline
\end{tabular}

\section{APPENDIX D APPLICATION}

Several tasks on the above mentioned components have been prepared by the researcher. Following task on summarizing is just an example.

\section{SUMMARIZING}

Summary is the gist or synopsis of a text. We are familiar with summary of a story or an essay. We summarize things in our day-to-day life. We summarize when we narrate the story of a film we have watched or a book we have read. We summarize when we narrate what all we did during the day or when we narrate an event.

Summarizing is a very important skill for a student. It helps them to store information and use it later. It saves their time. It also helps them to organize their studies. When we summarize, we give a faithful condensed version of the original text. In a summary we should not include our ideas as we do in writing a paraphrase. We also avoid citing examples given in the original text.

The following steps will help you summarize a passage

I. Read the passage carefully and underline the key information.

II. Prepare notes for each paragraph of the passage (text). Use short sentences.

III. Using these notes prepare a draft summary of the passage.

IV. Edit the draft summary and make a final summary of the passage.

Observe how the above mentioned steps have been applied to each of the following passages, to write summaries.

Passage 1

\section{The Learning of language}

When someone learns a language, he is not, properly speaking, gaining a knowledge of his environment. Language is no knowledge, but a set of skills. The teaching of it, therefore, must be different from the teaching of a 'content' subject like science... Of course, it is possible to study language or languages in the way we study history or geography or a science-as a 'content' subject, a set of concepts of varying degrees of abstraction. This is the way a linguist studies a language, so that he can analyse and describe it. This, too, requires skill, but it is the sort of skill a scientist needs rather than the language learner: There is many an academic linguist who is capable of giving an excellent description of a language in which he is only a mediocre performer.

The skills of performance and those of description are different, and the most intensive descriptive study of a language does not necessarily lead to an ability to communicate in or understand that language. It may, in certain circumstances, particularly with highly educated adult learners, help to do so, but it is not a necessary or an intrinsic part of learning a language.

Most aspects of everyday behaviour, including language, are learnt to a high degree of skill without any formal teaching. We have all learned, for example, to eat, walk and sleep without having been instructed in the physiological or anatomical aspects of those activities. We were taught them as skills, as behaviour, but not as a body of language.

Languages, then, can be learnt without the learner being given a linguistic description of the language, and learning a language is learning a set of skills. This is now becoming generally accepted, though not yet always acted upon. (310 words)

(S.Pitcorder: The Visual in Language Teaching (1966)

\section{Stage II}


When someone learns a language, he is not, properly speaking, gaining a knowledge of his environment. Language is no knowledge, but a set of skills. The teaching of it, therefore, must be different from the teaching of a 'content' subject like science... Of course, it is possible to study language or languages in the way we study history or geography or a science- as a 'content' subject, a set of concepts of varying degrees of abstraction. This is the way a linguist studies a language, so that he can analyse and describe it. This, too, requires skill, but it is the sort of skill a scientist needs rather than the language learner: There is many an academic linguist who is capable of giving an excellent description of a language in which he is only a mediocre performer.

The skills of performance and those of description are different, and the most intensive descriptive study of a language does not necessarily lead to an ability to communicate in or understand that language. It may, in certain circumstances, particularly with highly educated adult learners, help to do so, but it is not a necessary or an intrinsic part of learning a language.

Most aspects of everyday behaviour, including language, are learnt to a high degree of skill without any formal teaching. We have all learned, for example, to eat, walk and sleep without having been instructed in the physiological or anatomical aspects of those activities. We were taught them as skills, as behaviour, but not as a body of language.

Languages, then, can be learnt without the learner being given a linguistic description of the language, and learning a language is learning a set of skills. This is now becoming generally accepted, though not yet always acted upon. (310 words)

Notes

The Learning of Language

1. Lang not knwldg but skls: itss tchng must be difrnt from tchng content subjects.

1.1 Possible to study lang. as content subj- as done by linguists.

1.2 Linguist analyses and describes a lang.-needs -skls of description.

2. Skls of performance and skls of description are diffrnt. Skls of description to do not necessarily lead to skls of perfomance.

3. Lang. Like other daily habits is lrnt with little frml tchng.

3.1 Lang can be lrnt without giving any descript. of the lang.

3.2 Lang. Lrng. Lrng- leng a set of skls.

\section{Stage III}

Draft Summary

Language is not knowledge but a set of skills. Therefore its teaching must be different from teaching other content subjects. It is also possible to study language as a content subject, as done by linguists. A linguist studies a language, analyses and describes it. In order to do this he also needs skills- skills of description. These are different from the skills of performance. The former do not necessarily lead to the latter. Language, like eating and sleeping is learnt without any formal teaching. It can be learnt without the learner acquiring a description of it. It involves learning a set of skills.

\section{Stage IV}

Final Summary

Language is not knowledge but a set of skills. Therefore its teaching must be different from teaching other content subjects. It is also possible to study language as a content subject, as done by linguists. A linguist, who studies a language, analyses and describes it, also needs skills- the skills of description, which are different from the skills of performance. The former do not necessarily lead to the latter. Language, like eating and sleeping, is learnt without any formal teaching. It can be learnt without giving the learner a description of it. It involves learning a set of skills.

(96 words)

Notice that

- only the essential points are included in the notes

- the draft summary is written on the basis of the notes and not on the text

- the draft summary is further condensed

- necessary additions or deletions are made so as to make the summary read as a coherent piece of writingrepetitions are avoided

- the original text is about 310 words and the summary is about 97 words- nearly one third of the original.

\section{APPENDIX E APPRECIATION}




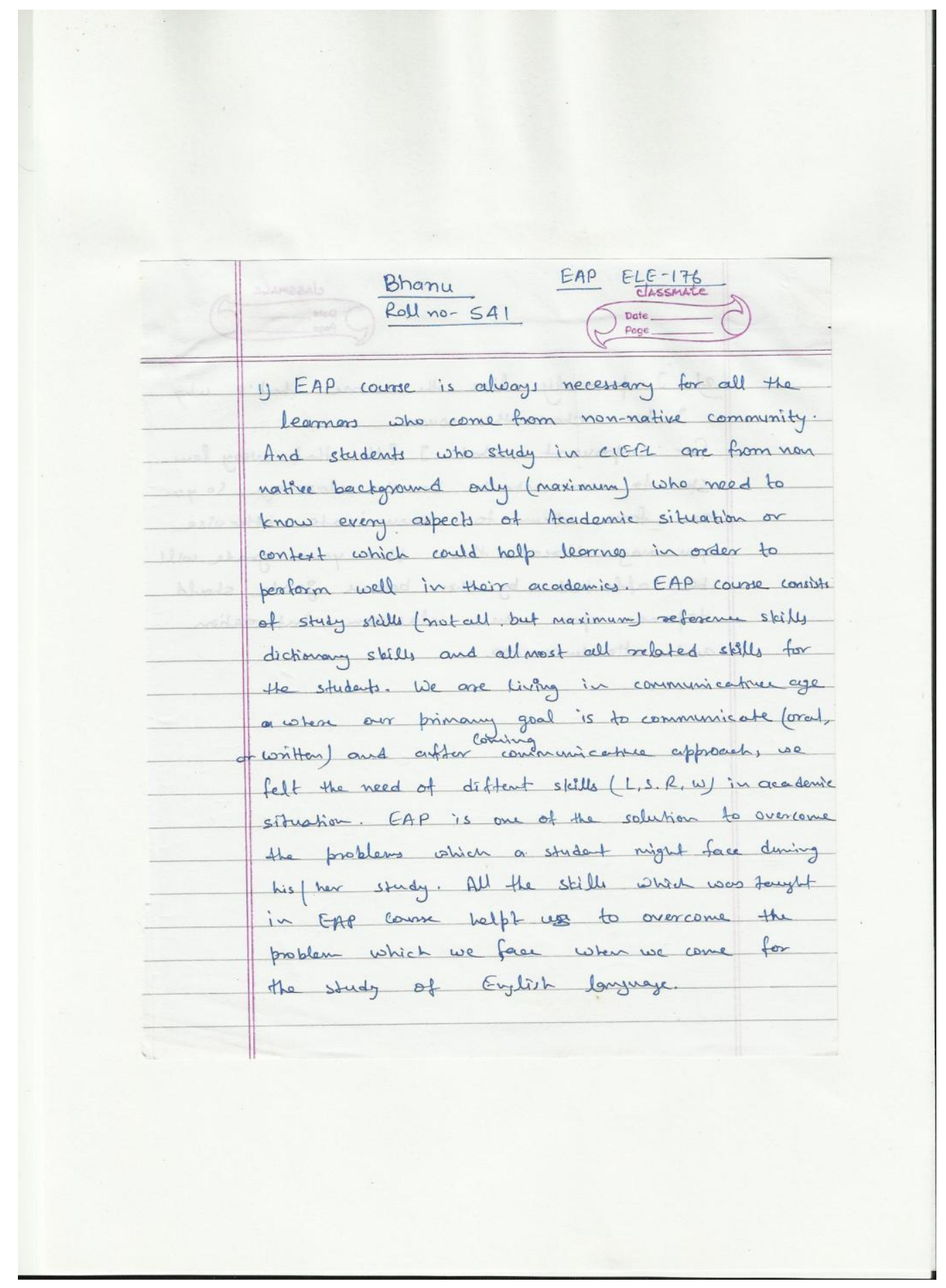




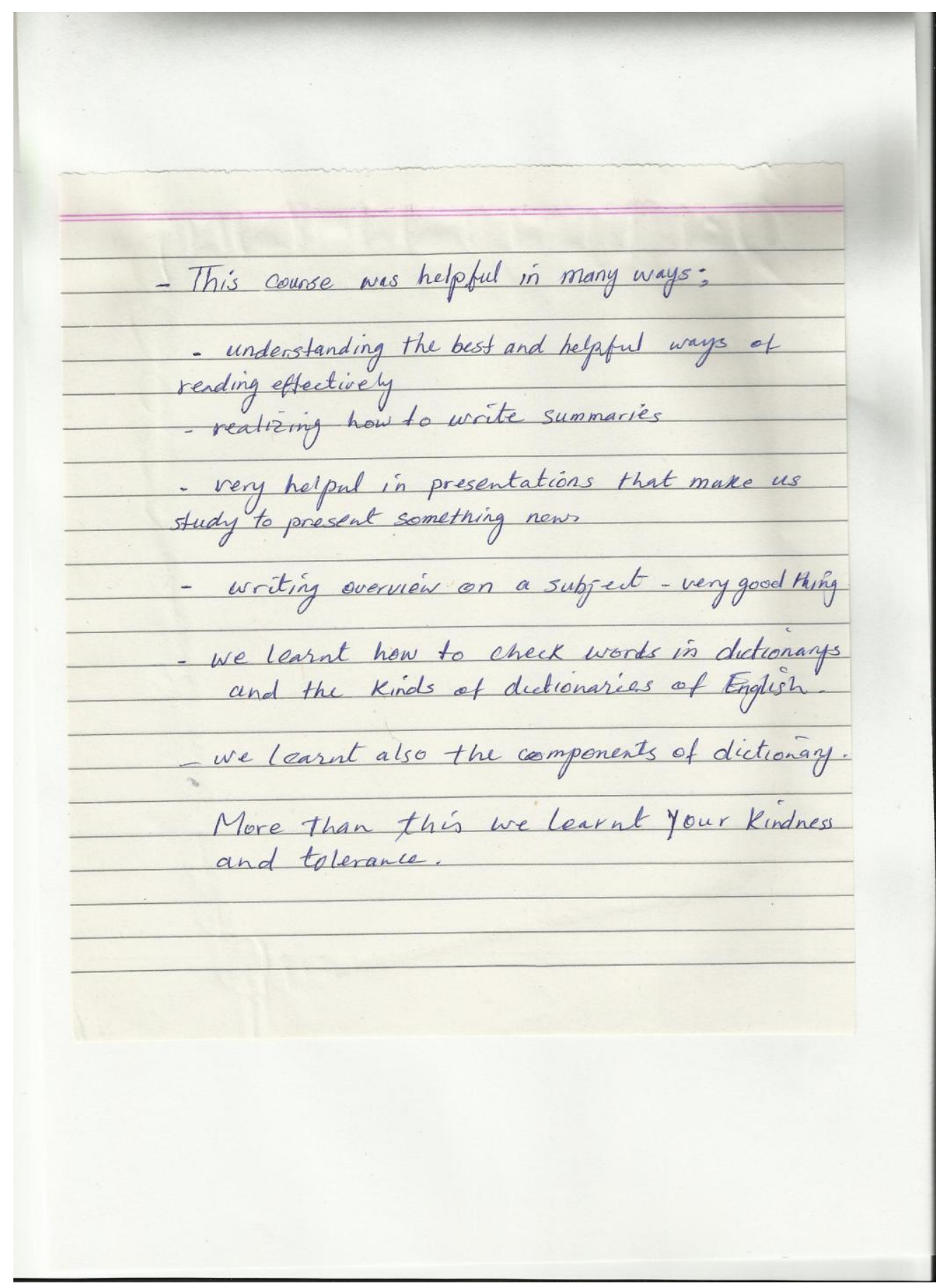

\section{REFERENCES}

[1] Brown, Clara Lee. (2004). Content based ESL curriculum and academic language proficiency. The Internet TESL Journal. 10. 2, 1-6. http//: web.ukt.edu/ tpte/scf_f_cb.html (Accessed20/02/2006)

[2] Wyk, Arlys, Van. (2006). Access to Higher Education in South Africa: Bridging the Divide Through Academic Literacy. TESOL Journal. 12.3, 29-34.

[3] Freeman, Yvonne and David Freeman. (2006). Struggling English Language Learners: Keys for Academic Success. TESOL Journal. 12.3, 5-10.

[4] Jordan, R.R. (2004). English for Academic Purposes. Cambridge: Cambridge UP.

[5] Swales, John. M. (1990). Genre Analysis: English in academic and research settings. Cambridge: Cambridge UP.

[6] Qian, David, D. (2007). Assessing university students: searching for an English language exit test. Regional language Centre Journal 38.1,18-84. 


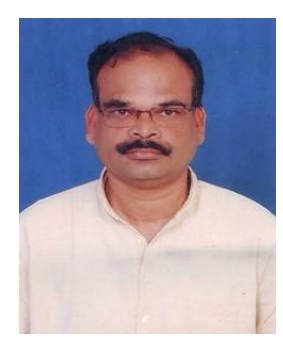

Anand Mahanand teaches English at the English and Foreign Languages University, Hyderabad, India. He is interested in Materials Development, English for Academic Purposes, Language through Literature and English in Multilingual Contexts. He has published books, materials and articles in these areas. His recent publication (with Lalita Goswami) includes- English through Folktale (Viva Books). 